\title{
A mobile application for the Liturgical planner-calendar of a Roman Catholic Diocese in the Philippines
}

Espinosa, Kevin Aldrin $\triangle$

Holy Angel University, Philippines (kaespinosa@hau.edu.ph; kevinaldrin.espinosa@gmail.com) Magbag, Avigail

Holy Angel University, Philippines (amagbag@hau.edu.ph; apmagbag@gmail.com)

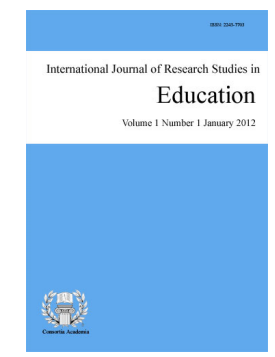

ISSN: 2243-7703 Online ISSN: 2243-7711

Received: 30 April 2020

Available Online: 6 July 2020

\section{Abstract}

The study aimed to develop a Liturgical Planner Application for a Roman Catholic Diocese in the Philippines. By using a mobile application, the members of the Clergy can manage their own liturgical calendar-planner, and a web application for the Chancery office to communicate important liturgical and administrative announcement to others. Descriptive-Quantitative method of research was used as research design, and Rapid Application Development was adopted to develop mobile and web applications. A total of 60 participants were selected using Purposive Sampling, with 56 members of the clergy, 2 Chancery Personnel, and 2 IT experts. The pre-survey instrument consisted of 10 questions, and the system evaluation instrument was based on the ISO 25010. Based on the results, the mobile and web applications are suitable for use by the Clergy and Chancery personnel with excellent ratings on all areas of software product quality in the evaluation. The mobile application provided the Clergy with a planner that integrated the Liturgical Calendar and a means for them to receive communications from the Chancery in real-time. On the other hand, the web application provided the Chancery office a method to disseminate announcements to the Clergy.

Keywords: Liturgical calendar; planner; liturgy; mobile application; ISO 25010 


\section{A mobile application for the Liturgical planner-calendar of a Roman Catholic Diocese in the Philippines}

\section{Introduction}

Today's generation of Christians innovates with wireless internet in their homes. They use different gadgets, including smartphones, tablets, and other portable electronic devices, have all-day internet access, and are socially interconnected. Anything is done quickly online, such as watching TV shows while posting the current reaction on social media. Young people play online games anywhere and with anyone on the planet (Cuyos, 2013). In addition, Ferrone (2013) stressed that the call to the active participation of the faithful is the goal to be considered because before the Second Vatican Council was convened, the Liturgy or the Eucharist belongs only to selected people or more just to the Clergy. The mass goers were naturally spectators during the celebration. The need to let the people know more the Mass is the main concern of the Second Vatican Council.

In 1969, Pope Paul VI promulgated the Constitution on the Sacred Liturgy. It is said that the Church has the vigor to its faithful to adopt more suitable to the need of the changing times. Moreover, the Church "desires that all the faithful should be led to that fully conscious and active participation in liturgical celebrations which is demanded by the very nature of the Liturgy" (Sacrosanctum Concilium, 1969). The people are called to make Liturgy as the summit of their prayer life through which the Constitution sees reasons to reform and promote Liturgy. Actually, it was not easy for the Church to change all in one time radically. Time and time again, different Popes have tried different approaches in implementing the Constitution on the Sacred Liturgy. St. John Paul II, through the Pontifical Council on Social Communications (2002), saw the media as an outlet of the historical and scientific process in which every Christian should see different advancements and look further in the discovery of the values of the resources in the whole of humankind.

The Pontifical Council on Social Communications (2002) sees the internet in many ways as the most powerful in a line of media (telegraph, telephone, radio, television, etc.). Many Christians have gradually disregarded time and time-space as some obstacles to communications. Individuals and groups who do not embrace this technology see its alarming effects. Furthermore, Pope Pius XII stated in his encyclical letter, "The Church sees these media as 'gifts of God' which, in accordance with his providential design, unite men in brotherhood and so help them to cooperate with his plan for their salvation" (Communio et Progressio, 1971, p. 2). The same is true with the Pontifical Council on Social Communication, which views the internet as a powerful medium.

Pope Emeritus Benedict XVI dedicated two themes of the World Communications Day message to social media. He believed that it could reinforce the unity of the Church and Family. He opened accounts on Twitter and YouTube as a way to communicate with his followers. The Pope saw social networking as "portals of truth and faith" and as "new space for evangelization" (Cuyos, 2012). Different technologies opened the way for the Church to communicate its evangelization. Liturgy, as an essential element of the life of Christian, should also adapt to the current trends and technologies as the Church promotes evangelization through technology. Meanwhile, Liturgy is defined as "an array of communal religious practices and rituals, above all the Mass" (Pokorsky, 2017). Furthermore, Liturgy is seen as an essential activity of the Church. Hence, proper timing and sequence should be arranged in all the activities of the Church. The Roman Catholic Church uses Liturgical Calendar as a mechanism to take note of all significant Feast and Celebrations so that the people may respond accordingly to the Liturgy.

On the other hand, the proper timing of Liturgy is based on the Liturgical Calendar of the Roman Catholic Church. Liturgical Calendar is defined as "part of Catholicism's decor, the ornamental mantle clock with Roman numerals that looks nice but which no one uses to tell time" (Heady, 2017, p. 19). Moreover, in an edict issued 
A mobile application for the Liturgical planner-calendar of a Roman Catholic Diocese in the Philippines

by Pope Paul VI (1969), it was stated that the reform in the Liturgical Calendar commenced in effect on January 1, 1970 which was published jointly by the Sacred Congregation of Rites and Consilium.

In support of the view of Paul VI on Liturgical Calendar, ROMCAL Application Programming Interface (API) was developed with a module that generates the Liturgical Calendar that is following the revised liturgical calendar for the Roman Catholic Church as approved by Pope Paul VI in Mysterrii Pachalis dated February 14, 1969. The output dates are based on the standard calendar years that runs from January 1 to December 31 alongside with the Liturgical Calendar that starts from the First Sunday of Advent to the Solemnity of Christ the King (Bath, 2001). There are many things to consider in preparing a Liturgical Calendar. Subsequently, Geering (2012) used the ROMCAL API in developing a Catholic Calendar Applications using Objective-C platform for the use of the Jesuit Conference in the United States of America.

It is essential to understand the process of how to determine the Liturgical Calendar of each year. Christmas always falls on December 25, but the movable feasts of the Church (Ash Wednesday, Holy Thursday, Goof Friday, Easter, Pentecost, etc.) are quite another matter. Easter usually falls between March 22 and April 25, 46 days before it is Ash Wednesday, and 49 days after Easter is the day of Pentecost (Martin, 2018). Easter plays an essential date in determining the movable feasts. "Dating of Easter to the lunar calendar. The fluctuations of this great feast from year to year may seem erratic, particularly because, for nearly everything else, we follow the solar calendar. Almost everything has a set date on a twelve-month cycle. But the lunar calendar, too, has a set a date for Easter. It is always the first Sunday after the first full moon after the vernal equinox, which is why in any given year it can never be earlier than March 22" (Patella, 2008, p. 100).

According to Cohen (2016), dating Easter in the Liturgical Calendar has been a source of disagreement among Christian Churches for more than 2000 years. The study focuses on the calculation of Easter's date, from its original coincidence with Passover in the Hebrew lunisolar calendar, through the political and sociological problems caused by differences among the methods used for calculating its date in the Roman solar calendar. Theologically, the date of Easter changes from year to year for different reasons. First, "the date has to be a Sunday because the crucifixion occurred on a Friday and the resurrection on a Sunday." Second, "the New Testament says the crucifixion took place during the Jewish holiday of Passover, which is celebrated for eight days following the first full moon of spring" (Steward, 2001, p. 80).

Following the lunar explanation, the Liturgical calendar is based on cycles of a movable and immovable feast. The Feast of the Nativity of the Lord is the principal immovable feast that is set on December 25. While Easter is the principal movable feast, and most of the other movable feasts are determined with respect to Easter. The date of Easter is defined to occur on Sunday following the ecclesiastical full moon that falls on or next after March 21. The ecclesiastical full moon is the day 14 of a lunation, where the day of the ecclesiastical new moon is considered as the first day. "The tables are based on the Metonic cycle, in which 235 mean synodic months contain 6939.688 days. Since nineteen Gregorian years contain 6939.6075 days, the dates of Moon's phases in a given year will recur on nearly the same dates nineteen years later. To prevent the 0.08 -day difference between the cycles from accumulating, the tables incorporate adjustments to synchronize the system over longer periods of time. Additional complications arise because the ecclesiastical lunations are of 29 or 30 integral days. The entire calendar involves a cycle of 5700000 years containing 2081882250 days, which are equated to 70499 175 lunations." After the cycle, the date of Easter repeats. (Urban \& Seidelman, 2012)

In the Philippine context, the Liturgical Calendar had to be adopted by different archdioceses and Diocese throughout the world to integrate different customs, feasts, and traditions. The Catholic Bishop Conference of the Philippines promulgated in 1975 to have a national Liturgical Calendar but with the inclusion of some customs and feasts that can be celebrated on a specific date, at the discretion of the Bishop, who is the head of the archdiocese or Diocese (Raas, 1994). The announcement of the news to the people formed by different media requires taking into account the distinctive characteristics of media. The Church now needs to understand the use of the internet. The importance of communicating effectively to the people, especially the youth who are 
Espinosa, K. A., \& Magbag, A.

immersed with different advanced technologies, and also for them to use it well (Pontifical Council on Social Communications, 2002).

The Catholic Church in the Philippines, specifically the Episcopal Commission on Liturgy of the Catholic Bishop's Conference of the Philippines, publishes the Liturgical Calendar every year called "Ordo". Each Diocese or Province has its liturgical commission that is in charge of crafting the liturgical calendar for its local territory. However, it is still upon the approval of its Ordinary or Bishop, who is the Diocese head. (General Norms for the Liturgical Year and the Calendar, 1969). "A growing number of parishes, dioceses, religious congregations, and church-related institutions, programs, and organizations of all kinds now make effective use of the internet for these and other purposes. Creative projects under Church sponsorship exist in some places on the national and regional levels" (Pontifical Council on Social Communications, 2002, p. 5). The Church strongly recommends the exchange of ideas and information through the use of technology with those experienced in the field and those who are newcomers. This is because the Church understands that the internet is a way of communication between the evangelizers and the people.

Mobile applications are IT software artifacts that are specifically developed for mobile operating systems installed on handheld devices, such as smartphones or tablet computers. Mobile applications are either pre-installed on mobile devices or downloaded from various mobile application stores such as Apple's iTunes store or Google's Play store (Hoehle \& Venkatesh, 2015). According to Hirata and Pichiliani (2014), mobile applications include calendars, browsers, and interactive maps, which are part of people's lives nowadays. Mobile collaboration enables different users in diverse locations to combine contribution synergistically in a convenient manner. Furthermore, the manual process adaptation to the automated process should comply with particular design guidelines for automatic adaption to be enhanced.

As mobile operating systems continue to grow, it has become a challenge for application developers to provide a versatile application in the competitive market. By looking at different platforms that have set the criteria and models in performing each of the requirements, mobile applications should look for different models in adapting to each of them. (Charkaoui, Lahmar, Marzak, \& Abdelbaki, 2016). The innovation of different trends that include mobile, cloud technologies, social media, paves the way to the democratization of computing and overloading of information. The development of various mobile applications that have the capability of the computing paradigm, which sees different bits of knowledge, has not yet been explored. The exploration of the dynamic calendar's complexity was based on minimum path computing (Koutsakis, Liagouras, \& Sayegh, 2014).

According to Statista, as of the second quarter of 2018, 88\% of smartphone users use Android Operating System developed by Google, while $11.9 \%$ use iOS developed by Apple. Android Operating System is mostly used among all operating systems in smartphones (Statista, 2018). Meanwhile, Strapi is an open-source Content Management System (CMS) it allows easy long-term content management through an administration panel. Its extensible plugin system includes Admin Panel, Authentication \& Permissions management, Content Management, API Generator, etc. Lastly, Strapi can host its servers to make one own the data (Burgy, 2018).

While there are means to build mobile applications and web applications, securing applications is also essential, especially those hosted in web servers. The web browser uses SSL/TLS protocol to set up a secure connection between the web browser and the west host server when website visitors access a website or web page using HTTPS protocol. The protocol is used to ensure the security of the webserver. It shows that the linkage between browser and server remains secret, and no network attacks could modify or access the information requested. The authenticity of the host server shows that web browsers can identify the server's identity and make sure that the web server's identity is correct. When web browsers cannot ensure the security of the server, they show warning (Patil, 2017).

The researchers identified the need for a Roman Catholic Diocese in the Philippines for a Liturgical Calendar that will be beneficial to its Chancery Office and the members of the Clergy. The researchers utilized the Input-Process-Output framework in the study. As for the Input, a review was conducted by the researchers

28 Consortia Academia Publishing (A partner of Network of Professional Researchers and Educators) 
A mobile application for the Liturgical planner-calendar of a Roman Catholic Diocese in the Philippines

reviewed related and reliable sources. Online articles, e-books, e-journals, and other available resources that are relevant to the Liturgical Calendar, were used to support the identification of the need of the locale. Meanwhile, the process included the survey of individuals who specialized in Liturgy and Pastoral and Diocesan Management, particularly the Bishop and Chancellor of a Diocese. Moreover, the researchers acquired sufficient data to design and develop a mobile application that contains factual content deemed helpful to the intended users. After the development of the mobile application, testing was conducted to check if the objectives of the research were met. The study's output was the mobile application of liturgical planner-calendar for a Diocese in the Philippines.

\subsection{Objectives of the study}

The general objective was to develop a Liturgical Planner-Calendar mobile application for a Roman Catholic Diocese in the Philippines. Specifically, the study aims to:

$>\quad$ to provide through a mobile application that automatically generates the Liturgical Days in the Liturgical Calendar,

$>\quad$ to allow the Chancery office to announce to the Clergy the important gathering of the Diocese, and;

$>\quad$ to organize the ministerial schedule such as Masses, Blessings, and other Clergy gatherings.

\section{Methodology}

\subsection{Research design}

The researchers used descriptive and quantitative research approach for this study. Descriptive research was used to describe characteristics of a population being studied; pre-development surveys and system evaluation surveys were conducted using a qualitative method. The researchers intended to seek approval, set the agreements, and look for suggestions through reviews and gather information to check the study's feasibility and necessity was needed in the future by the use of pre-development survey questionnaires. The researchers also used a post-development survey to validate if it met the objectives and followed the standard for application or software quality.

\subsection{Research participants}

Using the purposive sampling, the participants are the Chancellor, and the Chancery Staff in behalf of a Roman Catholic Bishop who manage the application, they were given pre-survey questionnaires as part of the requirement definition. The target number of respondents was 90, which amounted to the number of Clergy of a local Diocese. Only 56 members of the Clergy evaluated the mobile application. The Chancellor and the Chancery Staff evaluated the web application as future administrators of the system. Two (2) IT experts evaluated the front-end and back-end of the system.

\subsection{Research instrument}

The mobile application and web application evaluation tool were developed using ISO/IEC 25010. The model is the cornerstone of a product quality evaluation system. The quality model determines which quality characteristic is taken into account when evaluating the properties of a software product (Iso25000.com, 2019). For the clergy and chancery staff, Functional Suitability and Usability were the criteria they used to evaluate the mobile application and web application. For IT experts, Functional Suitability, Portability, Security, Reliability, Usability, Performance Efficiency, and Maintainability were the criteria used to evaluate the system. 


\subsection{Sources of data}

The researchers used the quantitative type of research to gather information about the proposed liturgical-planner mobile application. Close-ended questions were given to respondents during the pre-development survey to determine the study's feasibility. The researchers also gathered information on the expectation of the users in the proposed application. Interviews were concluded by the researchers to justify the need for the proposed mobile application. The researchers used both the library and the Internet sources to gather literature and studies related to the current research to establish the application's necessity.

\subsection{Research procedure}

The following procedure was followed by the researchers throughout the development and completion of the whole study. In the analysis stage, the researchers thought of possible research that could aid the Roman Catholic Diocese of Tarlac in communicating the Liturgical Calendar to its Clergy. The researchers aimed to get valid information from the Chancery office of the Roman Catholic Diocese of Tarlac. The researchers conducted a formal pre-survey to the Chancellor and the staff of the Chancery office, which represents the Bishop, who willingly agreed to participate in the survey. A meeting for the said survey was scheduled, and as soon as the survey was answered. The gathered data from the pre-survey that occurred were used to develop the web application and the mobile application. Different tools were used to design both the front-end and back-end of the mobile application in the designing phase. In the process of designing, a Use Case was used both the mobile application and the web application as a guide for development. A Data Dictionary was also used in the designing of the system's database.

In the development phase, developing the front-end is the first part of the mobile application the main framework used is React-Native, specifically the React Native Material Design and React Native Calendar, these components were used in developing the mobile application in integrating data from the webserver. The integration of the ROMCAL API to the React Native Calendar component to integrate the General Roman Liturgical Calendar to the mobile application calendar. In the second part developing the back-end and the web application, Strapi was used in developing the Content Management System of the mobile application, and it was real-time synchronize in the mobile application with the utilization of Node.Js. The database for connecting the Web Application to the Mobile Application is MongoDB, which presented the data in JSON format. While, in the testing phase, the researchers let the Clergy, Chancery staff, and IT Experts evaluate the application both for mobile application and web application. With the help of the pre-development survey analysis and a post-development survey analysis using ISO 25010, the application was tested if the objectives were met.

\subsection{Statistical treatment of data}

The data gathered were tabulated, organized, and interpreted using a quantitative type of treatment. The statistical treatment used in analyzing the pre-survey data was frequencies, number of cases, and percentages. While the statistical treatment used for the post-test data was Weighted Mean formula, standard deviation, and Likert Scale (5 - Excellent, 4 - Very Satisfactory, 3 - Satisfactory, 2 - Good and 1 - Poor) for the verbal interpretation of the mean rating (Table 1).

\section{Table 1}

Likert scale

\begin{tabular}{lll}
\hline & Weight & \multicolumn{1}{c}{ Verbal Interpretation } \\
\hline $4.21-$ & 5.00 & Excellent \\
$3.41-$ & 4.20 & Very Satisfactory \\
$2.61-$ & 3.40 & Satisfactory \\
$1.81-$ & 2.60 & Fair \\
$1.00-$ & 1.80 & Poor \\
\hline
\end{tabular}




\section{Results}

The Chancellor and the Chancery staff who answered on behalf of the Bishop strongly agreed that Liturgy is a fundamental part of a ministry in the Church. Furthermore, they agreed that the Liturgical Calendar plays a vital role in the life of the clergy. In accordance with the Vatican II call for active participation and the openness of the Church to technology, they strongly agree that technology will perform a vital role in the Church as time goes by. Also, planning for the liturgical activities is one of the main tasks of a clergy. Thus, the annually prepared ORDO Calendar of the Catholic Bishops' Conference of the Philippines is useful in every Clergy, parish, and Diocese. The Chancery Staff agreed that the Chancery office needs to inform the Clergy about the concerns which the Chancery office needs to communicate. On the other hand, the Chancellor agreed he uses calendar applications of smartphones. Finally, they both strongly agree that a system that will link the Clergy and the Chancery office will be useful to an Archdiocese or Diocese.

Table 2 shows the response of the Clergy as users of the mobile application. Based on the results, the respondents rated the mobile application with a weighted mean of $4.24(S D=0.12)$ with Verbal Interpretation of Excellent in terms of Functional Suitability. This means the mobile application provides correct information on the liturgical calendar, provides notifications of announcements, and serves as a liturgical planner for liturgical celebrations.

\section{Table 2}

Functional suitability of the mobile application

\begin{tabular}{lccc}
\hline \multicolumn{1}{c}{ Criteria } & $M$ & $S D$ & Verbal Interpretation \\
\hline $\begin{array}{l}\text { The mobile application has all the functions required. e.g., } \\
\text { Liturgical Calendar, Planner, Notification, etc. }\end{array}$ & 4.23 & 0.69 & Excellent \\
$\begin{array}{l}\text { The mobile application does what is appropriate and } \\
\text { correct. }\end{array}$ & 4.14 & 0.75 & Very Satisfactory \\
$\begin{array}{l}\text { The mobile application is precise in executing its } \\
\text { functions. }\end{array}$ & 4.18 & 0.69 & Very Satisfactory \\
$\begin{array}{l}\text { The mobile application facilitates the user's experience. } \\
\text { Weighted Mean }\end{array}$ & 4.41 & 0.68 & $\begin{array}{l}\text { Excellent } \\
\text { Excellent }\end{array}$ \\
\hline
\end{tabular}

Table 3 illustrates the response of the Clergy in terms of Usability and User Interface of the Mobile Application. The respondents rated the mobile application in terms of usability and user interface with a weighted mean of $4.28(S D=0.08)$ with a verbal interpretation of Excellent. This means that the mobile application has tools that can be used by the users and facilitates the users' data entry. The mobile application's design is also appropriate to the Clergy as users and is easy to operate and navigate.

Table 3

Usability and user interface of the mobile application.

\begin{tabular}{|c|c|c|c|}
\hline Criteria & $M$ & $S D$ & Verbal Interpretation \\
\hline $\begin{array}{l}\text { The mobile application has tools that are appropriate for } \\
\text { the users. }\end{array}$ & 4.29 & 0.71 & Excellent \\
\hline The mobile application facilitates the users' data entry. & 4.23 & 0.69 & Excellent \\
\hline The mobile application attributes are easy to operate. & 4.21 & 0.73 & Excellent \\
\hline $\begin{array}{l}\text { The mobile application alerts the users when an error } \\
\text { occurs. }\end{array}$ & 4.2 & 0.67 & Very Satisfactory \\
\hline The mobile application's design elements are appropriate. & 4.32 & 0.69 & Excellent \\
\hline $\begin{array}{l}\text { The mobile application's graphical elements are easy to } \\
\text { understand. }\end{array}$ & 4.43 & 0.66 & Excellent \\
\hline The mobile application's navigation is easy to understand. & 4.27 & 0.65 & Excellent \\
\hline Weighted Mean & 4.28 & & Excellent \\
\hline
\end{tabular}

\section{Discussion and conclusion}

Based on the gathered results and information from the related literatures and studies, the researchers 
Espinosa, K. A., \& Magbag, A.

formed the following conclusions:

The main goal of using the ROMCAL API was to develop applications that can generate Liturgical Calendar. The researchers aimed to develop a mobile application that generates a Liturgical Calendar. Based on the results, the researchers conclude that ROMCAL API can be integrated with hybrid applications.

The Pontifical Council on Social Communications asserted that parishes, dioceses, religious congregations, and church-related institutions, programs, and organizations of all kinds now make effective use of the internet for specific purposes. The researchers concluded that using Strapi as Content Management System; the Chancery office can notify the Members of the Clergy on the announcements made and providing copies of circular letters.

Hirata and Pichiliani pointed out that mobile applications, including calendars, browsers, and interactive maps, are part of people's lives nowadays. The researchers concluded based on the results that using mobile applications, Clergy can easily organize their ministerial schedule on a mobile application module.

The researchers conclude that the mobile application improves the communication of the Chancery office and the members of the Clergy, and it integrates the Liturgical Calendar using ROMCAL API with the usual calendars with planners. Through the hybrid application, the Chancery Office can quickly post announcements through the web application. Then, a notification will show up to the mobile application installed in the Android devices of the Clergy members.

\section{References}

Black, K. (2010). Business statistics: Contemporary decision making (6th ed.). John Wiley \& Sons.

Burgy, P. (2018, January). Building a static blog using Gatsby and Strapi. Retrieved from https://blog.strapi.io/building-a-static-website-using-gatsby-and-strapi/

Claretian Communications Foundation, Inc. (2017). The Catholic directory of the Philippines. Quezon City: Claretian Communications Foundation, Inc.

Cohen, B. (2016). The problem with the date of Easter. Mátria Digital.

Cuyos, S. (2013). Social media and the new evangelization. Manila: Communication Foundation for Asia.

Ferrone, R. (2013). The call to participation. Pastoral Music, 38(1), 22-30.

Geering, J. (2012). Catholic Diocese app. Midwestern Mac.

Heady, C. (2017). What is the Liturgical calendar? The Catholic Answer.

Hoehle, H., \& Venkatesh, V. (2015). Mobile application usability: Conceptualization and instrument development. MIS Quarterly, 39(2), 435-472. https://doi.org/10.25300/MISQ/2015/39.2.08

Iso25000.com. (2019). ISO 25010. Retrieved from https://iso25000.com/index.php/en/iso-25000-standards/iso-25010

Liagouras, G.-A., Sayegh, A., \& Koutsakis, P. (2014). A new location-aware calendar-based application. Springer Science+Business Media.

Martin, G. (2018). The meaning and origin of the expression: A movable feast. Retrieved from https://www.phrases.org.uk/meanings/movable-feast.html

Mobile OS market share 2018. (2018). Retrieved from

https://www.statista.com/statistics/266136/global-market-share-held-by-smartphone-operating-systems/

Patella, M. (2008). Dating Easter. Seer's Corner.

Patil, K. (2017). An insecure wild web: A large-scale study of effectiveness of web security mechanisms. ICTACT Journal on Communication Technology, 8(1), 1465-1471. https://doi.org/10.21917/ijct.2017.0217

Paul VI, \& Vatican II. (1963). Sacrosanctum concillium: The constitution on the sacred liturgy. Vatican City. Pichiliani, M., \& Hirata, C. M. (2014). Adaptation of single-user multi-touch components to support. Springer Science+Business Media New York. https://doi.org/10.1007/s11036-014-0512-0

Pokorsky, J. (2017). Liturgy and life. Retrieved from

32 Consortia Academia Publishing (A partner of Network of Professional Researchers and Educators) 
A mobile application for the Liturgical planner-calendar of a Roman Catholic Diocese in the Philippines https://www.thecatholicthing.org/2017/08/20/liturgy-and-life/

Pontifical Council for Social Communication. (2002). Ethics in internet. Vatican City.

Pontifical Council for Social Communications. (2002). The church and internet. Vatican City.

Pope Pius XII. (1971). Communio et progressio. Vatican City.

Steward, I. (2001). Easter is a quasicrystal. Scientific American.

https://doi.org/10.1038/scientificamerican0301-80 
Espinosa, K. A., \& Magbag, A.

34 Consortia Academia Publishing (A partner of Network of Professional Researchers and Educators) 